\title{
Relationship Between Burnout, Professional Behaviors, and Cost-Conscious Attitudes Among US Physicians
}

\author{
Liselotte N. Dyrbye, MD, MHPE ${ }^{1}$, Colin P. West, MD, PhD ${ }^{7}$, \\ Andrea Leep Hunderfund, MD, MHPE ${ }^{7}$, Christine A. Sinsky, MD², \\ Mickey Trockel, MD, PhD ${ }^{3}$, Michael Tutty, PhD'2, Lindsey Carlasare, $M B A^{2}$, \\ Daniel Satele, $B A^{4}$, and Tait Shanafelt, $M D^{3}$ \\ 'Mayo Clinic, Rochester, MN, USA; ${ }^{2}$ American Medical Association, Chicago, IL, USA; ${ }^{3}$ Stanford School of Medicine, Stanford, CA, USA \\ ${ }^{4}$ Department of Health Sciences Research, Mayo Clinic, Rochester, MN, USA.
}

BACKGROUND: Despite the importance of professionalism, little is known about how burnout relates to professionalism among practicing physicians.

OBJECTIVE: To evaluate the relationship between burnout and professional behaviors and cost-conscious attitudes.

DESIGN AND PARTICIPANTS: Cross-sectional study in a national sample of physicians of whom a fourth received a sub-survey with items exploring professional behaviors and cost-conscious attitudes. Responders who were not in practice or in select specialties were excluded.

MEASURES: Maslach Burnout Inventory and items on professional behaviors and cost-conscious attitudes.

KEY RESULTS: Among those who received the subsurvey 1008/1224 (82.3\%) responded, and 801 were eligible for inclusion. Up to one third of participants reported engaging in unprofessional behaviors related to administrative aspects of patient care in the last year, such as documenting something they did not do to close an encounter in the medical record $(243 / 759,32.0 \%)$. Fewer physicians reported other dishonest behavior (e.g., claiming unearned continuing medical education credit; 40/815, 4.9\%). Most physicians endorsed cost-conscious attitudes with over 75\% (618/821) agreeing physicians have a responsibility to try to control health-care costs and $62.9 \%(512 / 814)$ agreeing that cost to society is important in their care decisions regarding use of an intervention. On multivariable analysis adjusting for personal and professional characteristics, burnout was independently associated with reporting 1 or more unprofessional behaviors (OR 2.01, 95\%CI 1.47-2.73, $p<0.0001$ ) and having less favorable cost-conscious attitudes (difference on $6-24$ scale $-0.90,95 \% \mathrm{CI}-1.44$ to $-0.35, p=0.001)$. CONCLUSIONS: Professional burnout is associated with self-reported unprofessional behaviors and less favorable cost-conscious attitudes among physicians.

Received June 19, 2019

Accepted September 12, 2019

Published online November 16, 2019
KEY WORDS: professional burnout; physicians; professionalism; health care costs.

Abbreviations

EHRs Electronic health records

AMA

Electronic health records

MBI

Maslach Burnout Inventory

J Gen Intern Med 35(5):1465-76

DOI: $10.1007 / \mathrm{s} 11606-019-05376-\mathrm{x}$

(C) Society of General Internal Medicine 2019

\section{INTRODUCTION}

Professionalism is critical to achieving the ideals of the quadruple aim ${ }^{1}$ and retaining the public's trust in health care. ${ }^{2}$ Integrity, accountability, empathy, commitment to professional competency, and adhering to ethical standards are among the core tenets of professionalism. ${ }^{3}$ Upholding these tenets may become difficult, however, in the face of evolving technologies, constrained resources, changing market forces, and problems in health care delivery. ${ }^{3,4}$ For example, to comply with regulations and reporting requirements, electronic health records (EHRs) often contain required fields for physicians to document information that may not directly apply or be exactly true, but is the best available or only option, for a particular patient. Prompts informing physicians that patients may have to pay out of pocket for a test may lead to similar dilemmas about choosing the actual indication versus a covered indication. Additionally, reimbursement for services provided often necessitates completing and documenting components of the history and exam that may not be clinically warranted to provide patient care. As a result, physicians spend up to half of their work effort completing such tasks, ${ }^{5}$ taking them away from the most important (and often most rewarding) aspects of patient care and contributing to an alarmingly high prevalence of burnout. ${ }^{6}$

Despite the importance of professionalism, little is known about how burnout relates to professionalism among 
practicing physicians. Previous studies suggest burnout among residents and medical students is associated with inappropriate patient care practices, decreased empathy and altruism, cheating and dishonest behaviors, and suboptimal attitudes about prescribing, managing conflicts of interests, and reporting impaired colleagues. ${ }^{7-12}$ Studies of job satisfaction and physician distress broadly (as opposed to burnout specifically) have found correlation between job dissatisfaction, work frustration, and inappropriate prescribing practices and referral patterns ${ }^{13,14}$ that drive up health care costs. In contrast, studies of practice transformation that included expanded staffing models and more optimal team integration and task distribution show promising results with respect to both reduction in physician burnout and parallel reductions in cost of care. ${ }^{15}$ These findings suggesting physician burnout may impact professional behaviors and attitudes in potentially insidious ways.

To further explore these relationships, we conducted a national survey of practicing physicians that measured professional behaviors and attitudes and examined the relationship between burnout and professional behaviors and costconscious attitudes. We hypothesized that physicians experiencing symptoms of burnout would be more likely to report behaviors and attitudes that conflict with the fundamental tenets of professionalism.

\section{METHODS}

\section{Participants}

As previously described, ${ }^{16}$ we surveyed a sample of US physicians from all specialty areas in active practice according to the American Medical Association (AMA) Physician Masterfile. We oversampled physicians in specialties outside family medicine, general pediatrics, general internal medicine, and obstetrics/gynecology to ensure an adequate sample of physicians from each specialty. In October 2017, we e-mailed a cover letter with a link to an online survey to 83,291 physicians. A total of 27,071 physicians opened at least 1 invitation e-mail. Next, we mailed a paper version of the survey to a random sample of 5000 physicians who had not responded to the online survey. Of these, 270 were returned as undeliverable. The 30,456 physicians who opened at least 1 invitation e-mail and/or received a paper mailing of the survey were considered to have received an invitation to participate in the study. ${ }^{17}$ Participation was voluntary, and all responses were anonymous. A secondary survey of 476 nonresponders revealed no significant differences in burnout scores among participants in the two surveys suggest participants were representative of US physicians as a whole. ${ }^{17}$

Immediately after completing the core survey items, responders were randomly allocated to sub-surveys. For this study, we included those respondents who received the subsurvey containing items on professional behaviors and attitudes. We excluded responders who indicated they were retired or not in practice, and, due to the nature of the questions assessing professional behaviors and attitudes (described below), we also excluded anesthesiologists, pathologists, radiologists, and individuals who selected "other" as their specialty. The Stanford and Mayo Clinic Institutional Review Boards reviewed and approved the study.

\section{Survey Items}

Burnout. Burnout was measured using the Maslach Burnout Inventory (MBI), a validated measure considered the criterion standard. ${ }^{18-21}$ Burnout encompasses emotional exhaustion (score range 0 to 54), depersonalization (score range 0 to 30 ), and personal accomplishment (score range 0 to 48 ). Scores within each domain were used as continuous variables and categorized as low, intermediate, or high using established cutoffs. ${ }^{22}$ Consistent with prior studies, ${ }^{23-25}$ we considered physicians with a high score on the depersonalization $(\geq 10)$ and/or emotional exhaustion $(\geq 27)$ MBI sub-scales to have burnout. ${ }^{18}$

Measures of Professional Behaviors. The sub-survey included five items asking physician to report if they had engaged in various dishonest behaviors within the last year. Items were derived from the Physician Charter on Medical Professionalism and AMA Code of Ethics and inquired about honesty, accountability, and commitment to professional competence and ethical standards. ${ }^{3,26}$ These items were similar to previously published items on the topic. ${ }^{3,11,27,28}$ Specifically, we asked physicians if, over the last year, they had (1) documented something (such as a review of systems) they had forgotten to do so they could "close out" an encounter in the EHR, (2) documented a part of the physical exam they had not examined to justify a billing code, or (3) assigned an indication for a test that was different from why it was actually ordered so it would be reimbursed by the patient's insurance and the patient would not have to pay out of pocket. Additional survey items asked physicians to indicate if in the last year they had (4) not discussed all the treatment options with patients because they were too busy or (5) requested continuing medical education (CME) credit for a lecture, course, or other activity they had not attended. Response options to these five items were "yes," "no," and "not applicable." These items are shown in Appendix A.

Measures of Cost-Conscious Attitudes. We used 6 of 11 previously published items to assess physician's attitudes toward cost-conscious care. ${ }^{29-34}$ These 6 were chosen as they focused most directly on cost of care. For these items, respondents were asked to indicate their extent of agreement using a 4-point Likert scale $(1=$ strongly disagree, $2=$ moderately disagree, 3 = moderately agree, $4=$ strongly agree), consistent with prior studies. ${ }^{29,} 30$ Physicians' scores on the 11 -item costconsciousness instrument have been shown to inversely 
correlate with inpatient cost of care where physicians completed their residency training, providing supporting evidence for concurrent validity. ${ }^{30}$

\section{Statistical Analysis}

Standard descriptive statistics were calculated, dichotomizing responses to the cost-consciousness survey items as agree/ strongly agree versus disagree/strongly disagree for ease of result presentation. We also summarized responses to the professional behavior items as a single variable by calculating the number of "yes" responses for each respondent across the 5 professional behavior items. Similarly, we summarized responses to the cost-conscious attitudes items as a single variable by assigning responses a point value from 1 to 4 , with higher point values reflecting more favorable attitudes toward cost-conscious care (i.e., agreement with a more favorable cost-conscious attitude or disagreement with a less favorable cost-conscious attitude). These point values were summed to calculate an overall cost-consciousness score for each respondent, consistent with prior studies. ${ }^{29,}{ }^{30}$ The potential range of resulting scores was 6 to 24 , with higher scores indicating more favorable attitudes toward cost-conscious care.

Next, we explored associations between variables using Kruskal-Wallis, Fisher exact, or chi-squared tests, as appropriate. Logistic regression was performed to evaluate the relationship between burnout and individual professional behaviors and attitudes. We also conducted multivariable logistic and linear regression analyses to evaluate associations between all variables and (a) engaging in one or more unprofessional behaviors, (b) endorsing cost-conscious attitudes at the individual item level, and (c) overall cost-consciousness score. Multivariable models included age, gender, specialty, hours worked per week, number of nights on call per week, and primary practice setting in addition to one of the five burnoutrelated variables at a time: (a) overall burnout (high emotional exhaustion or high depersonalization), (b) high emotional exhaustion, (c) high depersonalization, (d) emotional exhaustion as a continuous variable, or (e) depersonalization as a continuous variable. We used a 5\% type I error rate and twosided alternative hypotheses. SAS version 9 (SAS Institute, Inc.) was used for all analysis.

\section{RESULTS}

As previously reported, ${ }^{16} 5197$ (17.1\%) of the 30,456 physicians who received an invitation to participate completed a survey. Of these 5197 responders, 1224 received the subsurvey and $1008(82.3 \%)$ responded to at least one item on this sub-survey. After excluding respondents who indicated they were not actively practicing or who indicated their specialty was pathology, radiology, anesthesiology, or "other," there were 841 physicians remaining in the study cohort.
Among this group, the median age was 52. Just over one third (312/836, 37.3\%) were women and 29.9\% (251/839) worked in primary care (Internal Medicine-General, General Practice, Family Medicine, Obstetrics/Gynecology, or Pediatrics-General). Median hours worked per week was 50.0, and the median number of nights on call per week was 1.0. The most common work setting was private practice $(48.2 \%, 405 /$ 840 ) with fewer working in academic medical centers $(27.4 \%$, $230 / 840)$, veterans affairs hospitals $(1.7 \%, 14 / 840)$, active military practice $(1.4 \%, 12 / 840)$, or other settings $(21.3 \%$, 179/840). The mean (SD) emotional exhaustion score was 24.3 (13.2) with $42.0 \%$ (351/835) having high emotional exhaustion. The mean (SD) depersonalization score was 7.2 (6.6) with $29.9 \%$ (250/837) having high depersonalization. Overall, $47.3 \%$ (396/837) reported symptoms of burnout.

\section{PROFESSIONAL BEHAVIORS AND COST-CONSCIOUS ATITUDES}

Self-reported professional behaviors in the last year and costconscious attitudes are shown in Table 1. Nearly one third of participating responders reported engaging in unprofessional behavior related to administrative aspects of patient care in the last year. Forty-three percent of physicians (362/841) indicated they had not engaged in any of the unprofessional behaviors explored, while 26.9\% (226/841), 17.0\% (143/841), $7.8 \%$ (66/ $841)$, and $5.3 \%$ (44/841) indicated they had engaged in 1, 2, 3, or $\geq 4$ behaviors, respectively.

Most physicians reported favorable beliefs regarding costconscious attitudes. The mean overall cost-consciousness score was 16.1 (SD 3.6, scale range 6-24).

\section{PROFESSIONAL BEHAVIORS AND BURNOUT}

Physicians experiencing symptoms of professional burnout were significantly more likely to have engaged in each unprofessional behavior evaluated (Table 1). The aggregate number of self-reported unprofessional behaviors increased as the severity of emotional exhaustion or depersonalization increased across low, intermediate, and high levels (using preestablished cut-off scores; both $p<0.0001$; Fig. 1a).

A similar relationship between burnout and unprofessional behaviors was found when the emotional exhaustion and depersonalization scores were treated as continuous variables (Table 2). Mean emotional exhaustion and depersonalization scores were also higher among physicians reporting a greater number of unprofessional behaviors (both $p<0.0001$; Fig. 2).

Factors independently associated with engaging in one or more unprofessional behavior are shown in Table 3. Professional burnout was independently associated with reporting at least one unprofessional behavior (OR 2.01, 95\% CI 1.47$2.73, p<0.0001)$ after adjusting for gender, age, specialty, hours worked per week, number of nights on call per week, and primary practice setting. Older physicians were less likely 
Table 1 Self-Reported Professional Behaviors in the Last Year and Cost-Conscious Attitudes Among Physicians With and Without Burnout

\begin{tabular}{|c|c|c|c|c|c|}
\hline & \multirow[t]{2}{*}{ Overall } & \multicolumn{2}{|l|}{$\overline{\text { Burnout }}$} & \multirow[t]{2}{*}{ OR (95\% CI) } & \multirow[t]{2}{*}{$p$ value } \\
\hline & & With & Without & & \\
\hline \multicolumn{6}{|l|}{ Professional behaviors } \\
\hline $\begin{array}{l}\text { Documented something (e.g., review of systems) had forgotten to do } \\
\text { so that could "close out" an encounter in the EHR. }\end{array}$ & $\begin{array}{l}243 / 759 \\
(31.9 \%)\end{array}$ & $\begin{array}{l}139 / 372 \\
(37.4 \%)\end{array}$ & $\begin{array}{l}103 / 387 \\
(26.6 \%)\end{array}$ & $\begin{array}{l}1.64 \\
(1.21-2.23)\end{array}$ & 0.002 \\
\hline $\begin{array}{l}\text { Documented a part of the physical exam that had not been examined } \\
\text { to justify a billing code. }\end{array}$ & $\begin{array}{l}148 / 795 \\
(18.6 \%)\end{array}$ & $\begin{array}{l}89 / 387 \\
(23.1 \%)\end{array}$ & $\begin{array}{l}59 / 410 \\
(14.4 \%)\end{array}$ & $\begin{array}{l}1.80 \\
(1.25-2.59)\end{array}$ & 0.002 \\
\hline $\begin{array}{l}\text { Assigned an indication for a test different from why really ordered so } \\
\text { that it would be reimbursed by the patients' insurance and the patient } \\
\text { would not have to pay out of pocket. }\end{array}$ & $\begin{array}{l}249 / 784 \\
(31.8 \%)\end{array}$ & $\begin{array}{l}150 / 377 \\
(40.0 \%)\end{array}$ & $\begin{array}{l}99 / 409 \\
(24.2 \%)\end{array}$ & 2.11 & $<0.0001$ \\
\hline $\begin{array}{l}\text { Did not discuss all treatment options with patients because was too } \\
\text { busy. }\end{array}$ & $\begin{array}{l}214 / 815 \\
(26.3 \%)\end{array}$ & $\begin{array}{l}136 / 390 \\
(34.9 \%)\end{array}$ & $\begin{array}{l}78 / 425 \\
(18.4 \%)\end{array}$ & $\begin{array}{l}2.40 \\
(1.74-3.31)\end{array}$ & $<0.0001$ \\
\hline Requested CME credit for a lecture, course, or activity not attended. & $\begin{array}{l}40 / 815 \\
(4.9 \%)\end{array}$ & $\begin{array}{l}28 / 387 \\
(7.2 \%)\end{array}$ & $\begin{array}{l}12 / 428 \\
(2.8 \%)\end{array}$ & $\begin{array}{l}2.51 \\
(1.28-4.91)\end{array}$ & 0.004 \\
\hline \multicolumn{6}{|c|}{$\begin{array}{l}\text { Cost-conscious attitudes } \\
\text { I try not to think about the cost to the health care system when making treatmen }\end{array}$} \\
\hline Disagree/strongly disagree* & $\begin{array}{l}513 \\
(62.1 \%)\end{array}$ & $\begin{array}{l}241 \\
(61.6 \%)\end{array}$ & $\begin{array}{l}272 \\
(62.5 \%)\end{array}$ & ref & \\
\hline Strongly agree/agree ${ }^{\dagger}$ & $\begin{array}{l}313 \\
(37.9 \%)\end{array}$ & $\begin{array}{l}150 \\
(38.4 \%)\end{array}$ & $\begin{array}{l}163 \\
(37.5 \%)\end{array}$ & $1.04(0.78-1.37)$ & 0.79 \\
\hline \multicolumn{6}{|c|}{ It is unfair to ask physicians to be cost-conscious and still keep the welfare of their patients foremost in their minds. } \\
\hline Disagree/strongly disagree* & $446 \%$ & 194 & 252.0 & ref & \\
\hline Strongly agree/agree ${ }^{\dagger}$ & $\begin{array}{l}382 \\
(46.1 \%)\end{array}$ & $\begin{array}{l}200 \\
(50.8 \%)\end{array}$ & $\begin{array}{l}182 \\
(41.9 \%)\end{array}$ & $1.43(1.09-1.88)$ & 0.01 \\
\hline \multicolumn{6}{|l|}{ Doctors are too busy to worry about the costs of tests and procedures. } \\
\hline Disagree/strongly disagree* & $\begin{array}{l}563 \\
(68.2 \%)\end{array}$ & $\begin{array}{l}232 \\
(59.3 \%)\end{array}$ & $\begin{array}{l}331 \\
(76.3 \%)\end{array}$ & ref & \\
\hline Strongly agree/agree ${ }^{\dagger}$ & $\begin{array}{l}262 \\
(31.8 \%)\end{array}$ & $\begin{array}{l}159 \\
(40.7 \%)\end{array}$ & $\begin{array}{l}103 \\
(23.7 \%)\end{array}$ & $2.20(1.63-2.97)$ & $<0.0001$ \\
\hline \multicolumn{6}{|c|}{ Cost to society is important in my decisions to use or not to use an intervention. } \\
\hline Strongly agree/agree* & $\begin{array}{l}512 \\
(62.9 \%)\end{array}$ & $\begin{array}{l}246 \\
(62.9 \%)\end{array}$ & $\begin{array}{l}266 \\
(62.9 \%)\end{array}$ & ref & \\
\hline Disagree/strongly disagree ${ }^{\dagger}$ & $\begin{array}{l}302 \\
(37.1 \%)\end{array}$ & $\begin{array}{l}145 \\
(37.1 \%)\end{array}$ & $\begin{array}{l}157 \\
(37.1 \%)\end{array}$ & $1.00(0.75-1.33)$ & 0.99 \\
\hline \multicolumn{6}{|l|}{ It is my responsibility to try to contain health care costs. } \\
\hline Strongly agree/agree* & $\begin{array}{l}618 \\
(75.3 \%)\end{array}$ & $\begin{array}{l}277 \\
(70.7 \%)\end{array}$ & $\begin{array}{l}341 \\
(79.5 \%)\end{array}$ & ref & \\
\hline Disagree/strongly disagree ${ }^{\dagger}$ & $\begin{array}{l}203 \\
(24.7 \%)\end{array}$ & $\begin{array}{l}115 \\
(29.3 \%)\end{array}$ & $\begin{array}{l}88 \\
(20.5 \%)\end{array}$ & $1.61(1.17-2.22)$ & 0.004 \\
\hline $\begin{array}{l}\text { There is currently too much emphasis on costs of tests and procedures. } \\
\text { Disagree/strongly disagree* }\end{array}$ & $\begin{array}{l}468 \\
(57.4 \%)\end{array}$ & $\begin{array}{l}219 \\
(56.7 \%)\end{array}$ & $\begin{array}{l}249 \\
(58.0 \%)\end{array}$ & ref & \\
\hline Strongly agree/agree ${ }^{\dagger}$ & 347 & 167 & $(42.0 \%)$ & $1.06(0.80-1.39)$ & 0.71 \\
\hline
\end{tabular}

Respondents were considered to have symptoms of burnout if they had high emotional exhaustion or high depersonalization scores (see the "Methods" section)

*Favorable

†Unfavorable

to report engaging in unprofessional behaviors (OR 0.98 for each year older, 95\% CI $0.97-1.00, p=0.02$ ) as were physicians who worked in academic medicine (referent private practice, OR $0.59,95 \%$ CI $0.41-0.86, p=0.01$ ).

Next, we repeated the multivariable models using emotional exhaustion or depersonalization as either dichotomous ("high" vs. "not high") or continuous variables in place of overall burnout. High emotional exhaustion was associated with an $87 \%$ increase in the odds of engaging in one or more unprofessional behaviors (OR 1.87, 95\%CI 1.37-2.56, $p<0.0001$; Appendix Table 4). High depersonalization was associated with over a twofold increase in the odds of engaging in one or more unprofessional behaviors (OR 2.43, 95\%CI 1.72$3.43, p<0.0001)$. For each 1-point increase in emotional exhaustion, the odds of reporting one or more unprofessional behaviors increased by 3\% (OR 1.03, 95\%CI 1.02-1.04, $p<$
0.0001; Appendix Table 5). Similarly, for each 1-point increase in depersonalization the odds of reporting one or more unprofessional behaviors increased by $9 \%$ (OR 1.09, 95\% CI $1.06-1.12, p<0.0001)$.

\section{COST-CONSCIOUS ATTITUDES AND BURNOUT}

On univariate analysis, a significant relationship was found between burnout and three of the six cost-conscious attitude items (Table 1). Likewise, a relationship was found between emotional exhaustion and depersonalization scores (treated as continuous variables) and the same three cost-conscious attitudes with less favorable attitudes associated with higher emotional exhaustion and depersonalization scores (Table 2). Overall cost-consciousness scores decreased as the severity of 
a

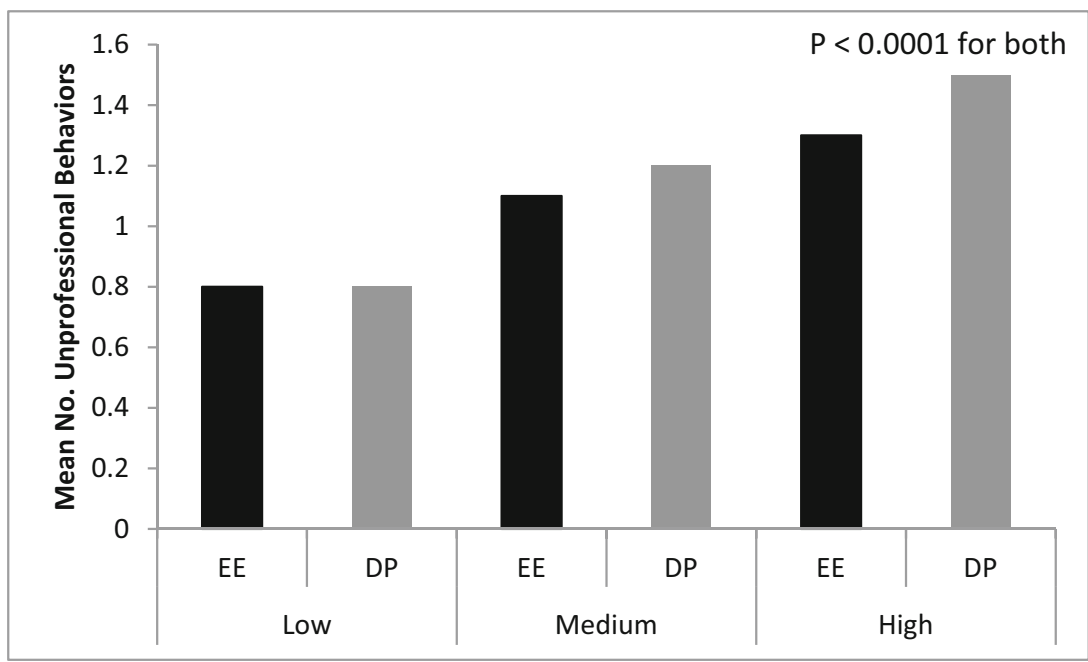

b

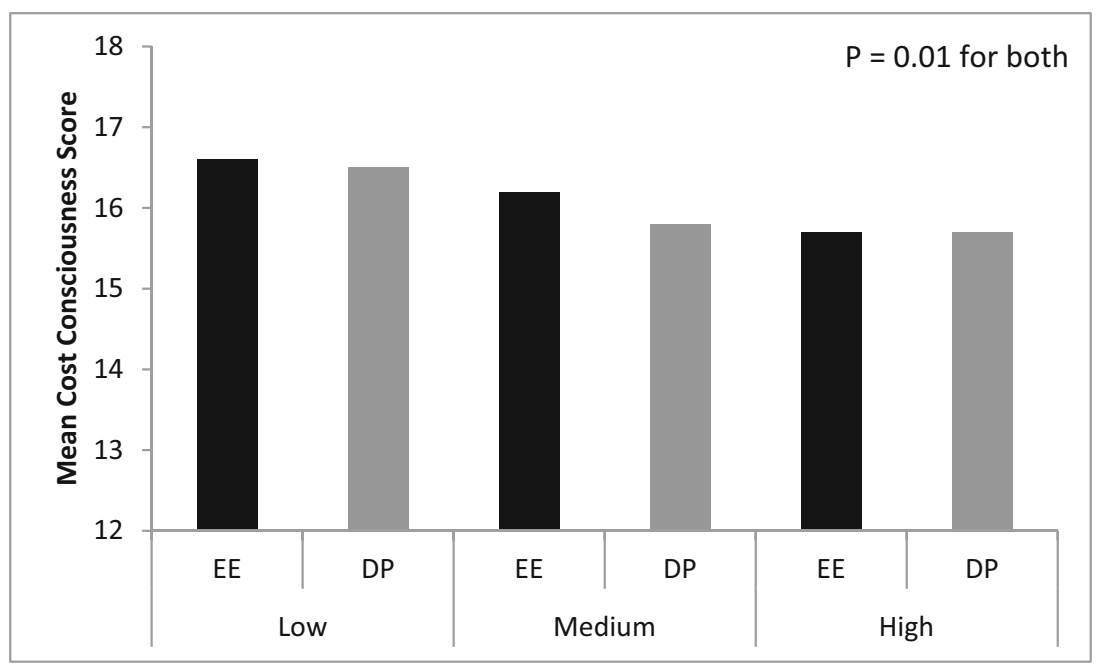

Figure 1 Mean number of unprofessional behaviors (a) and mean cost-consciousness score (b) reported by low, medium, and high emotional exhaustion (EE) score and depersonalization (DP) score. As the severity of emotional exhaustion and depersonalization increase, the number of reported unprofessional behaviors increases $(p<0.0001)$ and scores on the cost-consciousness scale decrease $(p=0.01)$.

emotional exhaustion or depersonalization increased across low, intermediate, and high levels (using pre-established cutoff scores, see the "Methods" section; both $p<0.01$; Fig. 1b).

On multivariable analysis, professional burnout remained an independent predictor of less favorable attitudes for the three cost-conscious attitudes items after adjusting for gender, age, specialty, hours worked per week, number of nights on call per week, and primary practice setting (Appendix Table 6). Moreover, burnout was independently associated with lower (less favorable) cost-consciousness scores (difference in score $-0.90,95 \% \mathrm{CI}-1.44$ to $-0.35 ; p=0.001$; Table 3). High emotional exhaustion (difference in score $0.85,95 \% \mathrm{CI}-1.40$ to $-0.30 ; p=0.003$ ) and high depersonalization (difference in score $-0.64,95 \% \mathrm{CI}-1.22$ to -0.06 ; $p=0.03$ ) were also independent predictors of costconsciousness scores (Appendix Table 7). Lastly, independent relationships were also found when emotional exhaustion and depersonalization were treated as continuous variables (Appendix Table 7).

\section{DISCUSSION}

In this large cohort of US physicians, self-reported unprofessional behaviors and less favorable cost-conscious attitudes were more common among those with professional burnout. These associations persisted after adjusting for other personal and professional characteristics. These findings have concerning implications given the high prevalence of burnout among US physicians ${ }^{35}$ and the critical role professionalism plays in ensuring the integrity of the health care delivery system.

Although it could be argued that physicians who adjust their indication for a test to reduce out-of-pocket cost for a patient 
Table 2 Self-Reported Professional Behaviors and Cost-Conscious Attitudes Among Physicians by Mean Emotional Exhaustion and Mean Depersonalization Scores

\begin{tabular}{|c|c|c|c|c|}
\hline & $\begin{array}{l}\text { Emotional exhaustion } \\
\text { score mean (SD) }\end{array}$ & $p$ value & $\begin{array}{l}\text { Depersonalization score } \\
\text { mean (SD) }\end{array}$ & $p$ value \\
\hline \multicolumn{5}{|l|}{ Professional behaviors } \\
\hline \multicolumn{5}{|c|}{ Documented something (e.g., review of systems) had forgotten to do so that could "close out" an encounter in the EHR. } \\
\hline Yes & $27.0(12.8)$ & $<0.01$ & $9.4(7.1)$ & \multirow[t]{2}{*}{$<0.0001$} \\
\hline No & $23.6(13.3)$ & & $6.5(6.4)$ & \\
\hline \multicolumn{5}{|c|}{ Documented a part of the physical exam that had not been examined to justify a billing code. } \\
\hline Yes & $27.0(12.8)$ & 0.01 & $10.0(7.2)$ & \multirow[t]{2}{*}{$<0.0001$} \\
\hline No & $24.0(13.1)$ & & $6.7(6.4)$ & \\
\hline \multicolumn{5}{|c|}{$\begin{array}{l}\text { Assigned an indication for a test different from why really ordered so that it would be reimbursed by the patient's insurance and the patient would not } \\
\text { have to pay out of pocket. }\end{array}$} \\
\hline Yes & $27.9(12.8)$ & $<0.0001$ & $9.2(7.2)$ & \multirow[t]{2}{*}{$<0.0001$} \\
\hline No & $22.8(12.9)$ & & $6.2(6.1)$ & \\
\hline \multicolumn{5}{|c|}{ Did not discuss all treatment options with patients because was too busy. } \\
\hline Yes & $28.1(12.9)$ & $<0.0001$ & $10.1(7.0)$ & \multirow{2}{*}{$<0.0001$} \\
\hline No & $23.2(13.0)$ & & $6.2(6.3)$ & \\
\hline \multicolumn{5}{|c|}{ Requested CME credit for a lecture, course, or activity not attended. } \\
\hline Yes & $28.9(13.1)$ & 0.03 & $10.6(8.0)$ & \multirow[t]{2}{*}{$<0.01$} \\
\hline No & $24.3(13.1)$ & & $7.0(6.6)$ & \\
\hline \multicolumn{5}{|l|}{ Cost-conscious attitudes } \\
\hline \multicolumn{5}{|c|}{ It is unfair to ask physicians to be cost-conscious and still keep the welfare of their patients foremost in their minds. } \\
\hline Disagree/strongly disagree* & $23.6(13.3)$ & 0.04 & $6.6(6.4)$ & \multirow[t]{2}{*}{0.004} \\
\hline Strongly agree/agree ${ }^{\dagger}$ & $25.4(12.9)$ & & $7.9(6.9)$ & \\
\hline \multicolumn{5}{|c|}{ Doctors are too busy to worry about the costs of tests and procedures. } \\
\hline Disagree/strongly disagree* & $22.8(13.1)$ & $<0.0001$ & $6.4(6.1)$ & \multirow{2}{*}{$<0.0001$} \\
\hline Strongly agree/agree ${ }^{\dagger}$ & $27.7(12.8)$ & & $9.1(7.3)$ & \\
\hline \multicolumn{5}{|c|}{ It is my responsibility to try to contain health care costs. } \\
\hline Strongly agree/agree* & $23.4(12.8)$ & $<0.001$ & $6.9(6.3)$ & \multirow[t]{2}{*}{0.04} \\
\hline Disagree/strongly disagree ${ }^{\dagger}$ & $27.4(13.9)$ & & $8.4(7.6)$ & \\
\hline \multicolumn{5}{|c|}{ Cost to society is important in my decisions to use or not to use an intervention. } \\
\hline Strongly agree/agree* & $24.3(13.3)$ & 0.48 & $7.4(6.7)$ & \multirow{2}{*}{0.36} \\
\hline Disagree/strongly disagree ${ }^{\dagger}$ & $24.8(13.0)$ & & $7.0(6.6)$ & \\
\hline \multicolumn{5}{|c|}{ There is currently too much emphasis on costs of tests and procedures. } \\
\hline Disagree/strongly disagree* & $24.2(13.4)$ & 0.62 & $7.1(6.6)$ & \multirow{2}{*}{0.55} \\
\hline Strongly agree/agree ${ }^{\dagger}$ & $24.6(12.8)$ & & $7.3(6.7)$ & \\
\hline \multicolumn{5}{|c|}{ I try not to think about the cost to the health care system when making treatment decisions. } \\
\hline Disagree/strongly disagree* & $24.6(13.2)$ & 0.56 & $7.5(6.8)$ & \multirow{2}{*}{0.20} \\
\hline Strongly agree/agree ${ }^{\dagger}$ & $23.9(13.0)$ & & $6.8(6.5)$ & \\
\hline
\end{tabular}

*Favorable

†Unfavorable

are doing so out of concern for the patient's welfare, such behavior is dishonest and conflicts with professional norms outlined in the AMA Code of Medical Ethics, the American College of Physicians Ethics Manual, and the Guide to Good Medical Practice. ${ }^{3,27,28}$ It also conflicts with the profession's collective responsibility to steward health care resources for the welfare of society and promote transparent business practices. $^{3,27,28,36}$ It is notable that a markedly higher proportion of physicians reported engaging in unprofessional behaviors related to administrative aspects of patient care (e.g., documenting something they had forgotten to do so they could "close out" an encounter in the EHR) than other types of unprofessional behaviors (e.g., claiming CME credit for a lecture, course, or activity they did not attend). Dilemmas, such as choosing between falsely indicating medication reconciliation in order to sign and close the chart (as no "not done" option exists) or leaving the chart open and risking reprimand, are common in today's practice environment. Physicians may feel compelled to "break a rule" (i.e., act in a way that conflicts with the tenets of professionalism) to achieve other goals (meet patient's needs, stay on time, timely completion of charts, etc.). Struggling with these types of trade- offs adds work-related stress and the administrative aspects of patient care often reduce time for meaningful patient interactions. Together, these may contribute to the "hundreds and thousands of tiny betrayals of purpose, each one so minute that it hardly attracts notice" 37 that contribute to burnout. Additional research is needed to identify, and ultimately eliminate, system-level factors (time pressures, EHR, institutional policies and procedures, etc.) that contribute to such ethical dilemmas and add undue burden.

Three of the unprofessional behaviors physicians endorsed could increase the cost of care (up coding, strategies to ensure reimbursement, not discussing low-cost approaches such as watch and wait). Furthermore, physicians who were burned out also had less favorable attitudes toward cost-conscious care, suggesting a lower capacity for or commitment to just distribution of finite resources. In particular, physicians with burnout were more likely to consider it unreasonable to expect physicians to be cost-conscious and still keep the welfare of their patients foremost in their minds. Similarly, physicians with burnout were twofold more likely to agree physicians were too busy to worry about the costs of tests and procedures and $60 \%$ less likely to agree they had a personal responsibility 


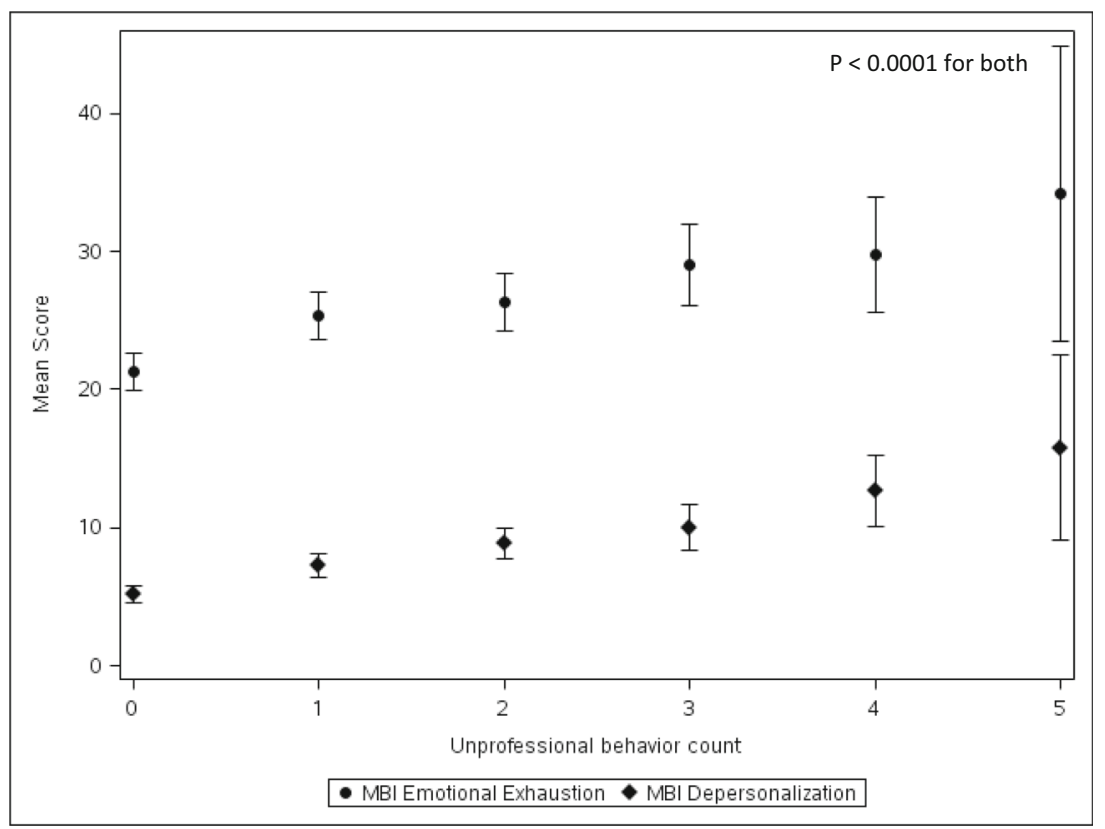

Figure 2 Mean emotional exhaustion score and depersonalization score by number of unprofessional behaviors reported. Maslach Burnout Inventory (MBI) Emotional exhaustion score ranges from 0 to 54 and depersonalization score ranges from 0 to 30 . Error bars indicate $95 \%$ confidence intervals. $p<0.0001$ by Kruskal-Wallis test for associations between number of unprofessional behaviors and emotional exhaustion or depersonalization score.

to try to contain health care costs. Such attitudes could contribute to increasing costs of care at a societal level, suggesting that burnout could contribute to health care cost beyond medical error and job turn-over. ${ }^{38}$

This study has a number of limitations. First, the participation rate was low. It should be noted, however, that our followup survey of non-responders (which had a high participation rate) found no statistically significant differences between participants with respect to age, years in practice, or burnout, suggesting that respondents were representative of US physicians $^{17}$ and mitigating concerns about response bias. ${ }^{39}$ Second, we evaluated self-reported unprofessional behavior by self-reported behavior, which may not accurately reflect actual unprofessional behavior in practice. Third, our study included

Table 3 Multivariable Analysis of Factors Associated with Reporting $\geq 1$ Unprofessional Behavior in the Last Year and Mean CostConsciousness Score

\begin{tabular}{|c|c|c|c|}
\hline$\geq 1$ Unprofessional behavior & OR $(95 \% \mathrm{CI})$ & $p$ value & Overall $p$ value \\
\hline Burnout* & $2.01(1.47-2.73)$ & & $<0.0001$ \\
\hline Male vs. female & $0.93(0.68-1.29)$ & & 0.67 \\
\hline Age (for each year older) & $0.98(0.97-1.00)$ & & 0.02 \\
\hline Internal medicine or pediatric subspecialty (vs. primary care) & $0.88(0.60-1.30)$ & 0.52 & 0.27 \\
\hline Other medical specialty (vs. primary care) & $1.12(0.72-1.74)$ & 0.63 & \\
\hline Surgical specialty (vs. primary care) & $0.73(0.48-1.10)$ & 0.13 & \\
\hline Hours per week (for each additional hour) & $1.00(1.00-1.01)$ & & 0.39 \\
\hline Nights on call per week (for each additional night) & $0.97(0.90-1.04)$ & & 0.33 \\
\hline Academic medical center (vs. private practice) & $0.59(0.41-0.86)$ & 0.01 & 0.02 \\
\hline Active military (vs. private practice) & $0.42(0.12-1.43)$ & 0.16 & \\
\hline Other practice (vs. private practice) & $0.90(0.61-1.33)$ & 0.60 & \\
\hline Veterans hospital (vs. private practice) & $0.31(0.10-1.01)$ & 0.051 & \\
\hline Cost-conscious attitude score ${ }^{\dagger}$ & Parameter estimate $(95 \% \mathrm{CI})$ & $p$ value & Overall $p$ value \\
\hline Burnout* & $-0.90(-1.44,-0.35)$ & & 0.001 \\
\hline Male vs. female & $0.01(-0.55,0.58)$ & & 0.96 \\
\hline Age (for each year older) & $0.002(-0.02,0.03)$ & & 0.85 \\
\hline Internal medicine or pediatric subspecialty (vs. primary care) & $-0.11(-0.89,0.67)$ & 0.79 & 0.99 \\
\hline Other medical specialty (vs. primary care) & $-0.04(-0.74,0.65)$ & 0.90 & \\
\hline Surgical specialty (vs. primary care) & $-0.07(-0.82,0.67)$ & 0.84 & \\
\hline Hours per week (for each additional hour) & $0.01(-0.009,0.03)$ & & 0.38 \\
\hline Nights on call per week (for each additional night) & $-0.07(-0.19,0.06)$ & & 0.30 \\
\hline Academic medical center (vs. private practice) & $0.85(0.20,1.51)$ & 0.01 & 0.06 \\
\hline Active military (vs. private practice) & $-1.34(-3.51,0.84)$ & 0.23 & \\
\hline Other practice (vs. private practice) & $0.36(-0.33,1.05)$ & 0.30 & \\
\hline Veterans hospital (vs. private practice) & $-0.06(-2.08,1.96)$ & 0.96 & \\
\hline
\end{tabular}

*High emotional exhaustion or high depersonalization scores (see the "Methods" section)

tHigher score corresponds to more favorable cost-conscious attitudes, range 6-24 
a limited number of behaviors and attitudes representative of professionalism. However, the increased odds of unprofessional behavior among burned out physicians held for all the unprofessional behaviors and persisted when burnout scale scores were treated as dichotomous or continuous variables, suggesting a broad effect. The observed relationship between burnout and professional behavior is also consistent with the findings of a multi-institutional study of burnout and professional behaviors among medical students. ${ }^{10}$ Fourth, our 6-item cost-consciousness scale was derived from an existing 11-item cost-conscious instrument. Fifth, although this study shows associations between burnout and professional behaviors as well as less favorable cost-conscious attitudes, we cannot determine if these relationships are causal or the potential direction of effect. For example, physicians who have symptoms of burnout may be more likely to engage in unprofessional behaviors; alternatively, physicians who engage in unprofessional behaviors may experience cognitive dissonance and be more vulnerable to developing symptoms of burnout.

\section{CONCLUSIONS}

In conclusion, this large national study of US physicians from diverse specialties and practice settings shows burnout is associated with unprofessional behaviors and less favorable attitudes toward cost-conscious care. The findings suggest burnout threatens the integrity of the health care delivery system and could contribute to health care cost beyond medical error and job turn-over. Additional studies are needed to better understand these associations and determine whether interventions to reduce burnout could ultimately strengthen professionalism and reduce the cost of care.

Corresponding Author: Liselotte N. Dyrbye, MD, MHPE; Mayo Clinic, Rochester, MN, USA (e-mail: dyrbye.liselotte@mayo.edu).

Funding Funding for this study was provided by the Mayo Clinic Department of Medicine Program on Physician Well-Being, the Stanford WellMD Center, and the American Medical Association. Funding sources had no role in study design; in the collection, analysis, and interpretation of data; in the writing of the report; and in the decision to submit the article for publication

\section{Compliance with Ethical Standards:}

Conflict of Interest: The authors declare that they do not have a conflict of interest.

\section{REFERENCES}

1. Bodenheimer T, Sinsky C. From triple to quadruple aim: care of the patient requires care of the provider. Ann Fam Med. 2014;12:573-6.

2. Wynia MK, Papadakis MA, Sullivan WM, Hafferty FW. More than a list of values and desired behaviors: a foundational understanding of medical professionalism. Acad Med. 2014;89:712-4.

3. American Board of Internal Medicine, American College of PhysiciansAmerican Society of Internal Medicine, European Federation of Internal
Medicine. Medical professionalism in the new millennium: a physician charter. Ann Intern Med 2002;136:243-6.

4. West CP, Shanafelt TD. The influence of personal and environment factors on professionalism in medical education. BMC Med Educ 2007 30;7:29 https://www.ncbi.nlm.nih.gov/pubmed/17760986

5. Sinsky C, Colligan $\mathbf{L}, \mathbf{L i} \mathbf{L}$, et al. Allocation of physician time in ambulatory practice: a time and motion study in 4 specialties. Ann Intern Med. 2016;165:753-60.

6. Shanafelt T, Dyrbye LN, Sinsky C, et al. Relationship between clerical burden and characteristics of the electronic environment with physician burnout and professional satisfaction. Mayo Clin Proc. 2016;91:836-48.

7. Shanafelt $\mathbf{T}$, Bradley $\mathbf{K}$, Wipf $\mathbf{J}$, Back $\mathbf{A}$. Burnout and self-reported patient care in an internal medicine residency program. Ann Intern Med. 2002; 136:358-67.

8. Shanafelt TD, West $\mathbf{C}$, Zhao $\mathbf{X}$, et al. Relationship between increased personal well-being and enhanced empathy among internal medicine residents. J Gen Intern Med. 2005;20:559-64.

9. Thomas MR, Dyrbye LN, Huntington JL, et al. How do distress and well-being relate to medical student empathy? A multicenter study. J Gen Intern Med. 2007;22:177-83.

10. Dyrbye LN, Massie FS, Jr., Eacker A, et al. Relationship between burnout and professional conduct and attitudes among US medical students. JAMA. 2010;304:1173-80.

11. Dyrbye LN, West CP, Satele D, Boone S, Sloan J, Shanafelt TD. A national study of medical students' attitudes toward self-prescribing and responsibility to report impaired colleagues. Acad Med 2015;90:485-93.

12. Passalacqua SA, Segrin C. The effect of resident physician stress, burnout, and empathy on patient-centered communication during the long-call shift. Health Commun. 2012;27:449-56.

13. Melville A. Job satisfaction in general practice: implications for prescribing. Soc Sci Med. 1980;14A:495-9.

14. Grol R, Mokkink H, Smits A, et al. Work satisfaction of general practitioners and the quality of patient care. Fam Pract. 1985;2:128-35.

15. Reid RJ, Coleman K, Johnson EA, et al. The Group Health medical home at year two: cost savings, higher patient satisfaction, and less burnout for providers. Health affairs (Project Hope) 2010;29:835-43.

16. Shanafelt T, West CP, Sinsky C, et al. Changes in burnout and satisfaction with work-life integration in physicians and the general US working population between 2011-2017. Mayo Clin Proc In press (ePub available).

17. (AAPOR): Aafpor. Standard Definitions: Final Dispositions of Case Codes and Outcome Rates for Surveys. 2011.

18. Maslach C, Jackson S, Leiter M. Maslach Burnout Inventory Manual. 3rd ed. Palo Alto: Consulting Psychologists Press; 1996.

19. Rafferty JP, Lemkau JP, Purdy RR, Rudisill JR. Validity of the Maslach Burnout Inventory for family practice physicians. J Clin Psychol 1986;42:488-92.

20. Lee RT, Ashforth BE. A meta-analytic examination of the correlates of the three dimensions of job burnout. J Appl Psychol 1996;81:123-33.

21. Leiter M, Durup J. The discriminant validity of burnout and depression: a confirmatory factor analytic study. Anxiety Stress Copin 1994;7:357-73.

22. Maslach C. Maslach Burnout Inventory Manual. Palo Alto: Consulting Psychologists Press; 1986.

23. Thomas NK. Resident burnout. JAMA 2004;292:2880-9.

24. Shanafelt TD, Bradley KA, Wipf JE, Back AL. Burnout and selfreported patient care in an internal medicine residency program. Annals of Internal Medicine 2002;136:358-67.

25. Rosen IM, Gimotty PA, Shea JA, Bellini LM. Evolution of sleep quantity, sleep deprivation, mood disturbances, empathy, and burnout among interns. Academic Medicine : journal of the Association of American Medical Colleges 2006;81:82-5.

26. Code of Medical Ethics. at https://www.ama-assn.org/delivering-care/ ethics/code-medical-ethics-overview. accessed 6 Nov 2019

27. American Medical Association. AMA Code of Medical Ethics. Opinion 9.031. Reporting Impaired, Incompetent, or Unethical Colleagues. Accessed at https://www.ama-assn.org/delivering-care/ethics/reporting-incompetent-orunethical-behaviors-colleagues. accessed 6 Nov 2019

28. Sulmasy LS, Bledsoe TA, for the ACP Ethics P, Committee HR. American College of Physicians Ethics Manual: Seventh Edition ACP Ethics Manual. Annals of Internal Medicine 2019;170:S1-S32.

29. Tilburt JC, Wynia MK, Sheeler RD, et al. Views of US physicians about controlling health care costs. JAMA 2013;310:380-8.

30. Ryskina KL, Halpern SD, Minyanou NS, Goold SD, Tilburt JC. The role of training environment care intensity in US physician cost consciousness. Mayo Clinic Proceedings 2015;90:313-20.

31. Antiel RM, Curlin FA, James KM, Tilburt JC. Physicians' beliefs and U.S. health care reform—a national survey. N Eng J Med 2009;361:e23. 
32. Goold SD, Hofer T, Zimmerman M, Hayward RA. Measuring physician attitudes toward cost, uncertainty, malpractice, and utilization review. J Gen Intern Med 1994;9:544-9.

33. Hurst SA, Slowther AM, Forde R, et al. Prevalence and determinants of physician bedside rationing: data from Europe. $J$ Gen Intern Med 2006;21:1138-43.

34. Kirchhoff AC, Hart G, Campbell EG. Rural and urban primary care physician professional beliefs and quality improvement behaviors. The Journal of Rural Health : official journal of the American Rural Health Association and the National Rural Health Care Association 2014;30:235-43.

35. Shanafelt TD, Hasan O, Dyrbye LN, et al. Changes in burnout and satisfaction with work-life balance in physicians and the general US working population between 2011 and 2014. [Erratum appears in Mayo Clin Proc. 2016 Feb;91(2):276]. Mayo Clin Proc 2015;90:1600-13.

36. National Alliance for Physician Competence. Guide to good medical practice-USA. 2008: available at http://www.ama-assn.org/amal/pub/ upload/mm/377/ggmp-usa.pdf, accessed 2/27/2014.

37. Gunderman R. For the young doctor about to burnout out. The Atlantic 2014

38. Shanafelt T, Goh J, Sinsky C. 2017 The business case for investing in physician well-being. JAMA Intern Med;177:1826-32.

39. Johnson TP, Wislar JS. Response rates and nonresponse errors in surveys. JAMA 2012;307:1805-6.

Publisher's Note Springer Nature remains neutral with regard to jurisdictional claims in published maps and institutional affiliations.

\section{APPENDIX 1}

Survey items related to professional behaviors and costconscious behaviors

1. In the last year, was there an instance where you did one of the following?

(a) Documented you did something (e.g., review of systems) you had forgotten to do so that you could "close out" an encounter in the EHR.

(b) Documented a part of the physical exam that had not been examined to justify a billing code. (c) Assigned an indication for a test different from why you really ordered it so that it would be reimbursed by the patients insurance and the patient would not have to pay out of pocket.

(d) Did not discuss all treatment options with a patient because you were too busy.

(e) Requested CME credit for a lecture, course, or activity that you did not attend.

Response options: yes, no, not applicable

2. Please rate your level of agreement or disagreement with the following statements.

(a) It is unfair to ask physicians to be cost-conscious and still keep the welfare of their patients foremost in their minds.

(b) Doctors are too busy to worry about the costs of test and procedures.

(c) It is my responsibility to try to contain health care costs. ${ }^{\text {a }}$

(d) Cost to society is important in my decisions to use or not to use an intervention.

(e) There is currently too much emphasis on costs of test and procedures.

(f) I try not to think about the cost to the health care system when making treatment decisions.

Response options: 1 = strongly disagree, 2 = moderately disagree, $3=$ moderately agree, $4=$ strongly agree

a Modified from original, "Trying to contain costs is the responsibility of every physician"

\section{APPENDIX 2}

Table 4 Multivariable Analysis of Factors Associated with Reporting $\geq 1$ Unprofessional Behaviors in the Last Year, with Overall Burnout Replaced by Either High Emotional Exhaustion or High Depersonalization

\begin{tabular}{|c|c|c|c|}
\hline & OR (95\% CI) & $p$ value & Overall $p$ value \\
\hline \multicolumn{4}{|l|}{$\geq 1$ Unprofessional behavior } \\
\hline High emotional exhaustion* & $1.87(1.37,2.56)$ & & $<0.0001$ \\
\hline Male vs. female & $0.95(0.69,1.32)$ & & 0.77 \\
\hline Age (for each year older) & $0.98(0.97,0.99)$ & & 0.01 \\
\hline Internal medicine or pediatric subspecialty (vs. primary care) & $1.07(0.69,1.67)$ & 0.76 & 0.24 \\
\hline Other medical specialty (vs. primary care) & $0.88(0.59,1.30)$ & 0.52 & \\
\hline Surgical specialty (vs. primary care) & $0.70(0.46,1.06)$ & 0.09 & \\
\hline Hours per week (for each additional hour) & $1.00(0.99,1.01)$ & & 0.45 \\
\hline Nights on call per week (for each additional night) & $0.97(0.91,1.04)$ & & 0.36 \\
\hline Academic medical center (vs. private practice) & $0.60(0.42,0.87)$ & 0.01 & 0.03 \\
\hline Active military (vs. private practice) & $0.42(0.12,1.46)$ & 0.17 & \\
\hline Other practice (vs. private practice) & $0.92(0.62,1.36)$ & 0.68 & \\
\hline Veterans hospital (vs. private practice) & $0.33(0.10,1.06)$ & 0.06 & \\
\hline \multicolumn{4}{|l|}{$\geq 1$ Unprofessional behavior } \\
\hline High depersonalization* & $2.43(1.72,3.43)$ & & $<0.0001$ \\
\hline Male vs. female & $0.83(0.60,1.15)$ & & 0.27 \\
\hline Age (for each year older) & $0.99(0.97,1.00)$ & & 0.03 \\
\hline Internal medicine or pediatric subspecialty (vs. primary care) & $1.08(0.69,1.68)$ & 0.74 & 0.25 \\
\hline Other medical specialty (vs. primary care) & $0.84(0.57,1.25)$ & 0.40 & \\
\hline
\end{tabular}


Table 4. (continued)

\begin{tabular}{|c|c|c|c|}
\hline & OR $(95 \% \mathrm{CI})$ & $p$ value & $\overline{\text { Overall } p \text { value }}$ \\
\hline Surgical specialty (vs. primary care) & $0.71(0.47,1.08)$ & 0.11 & \\
\hline Hours per week (for each additional hour) & $1.01(1.00,1.02)$ & & 0.27 \\
\hline Nights on call per week (for each additional night) & $0.97(0.91,1.04)$ & & 0.44 \\
\hline Academic medical center (vs. private practice) & $0.59(0.41,0.86)$ & 0.01 & 0.02 \\
\hline Active military (vs. private practice) & $0.41(0.12,1.44)$ & 0.16 & \\
\hline Other practice (vs. private practice) & $0.89(0.60,1.33)$ & 0.58 & \\
\hline Veterans hospital (vs. private practice) & $0.33(0.10,1.05)$ & 0.06 & \\
\hline
\end{tabular}

*High depersonalization $(\geq 10)$ and high emotional exhaustion $(\geq 27)$ using established cut-off scores

\section{APPENDIX 3}

Table 5 Multivariable Analysis of Factors Associated with Reporting $\geq 1$ Unprofessional Behaviors in the Last Year, with Overall Burnout Replaced by Either Emotional Exhaustion or Depersonalization as Continuous Variables

\begin{tabular}{|c|c|c|c|}
\hline & OR $(95 \%$ CI $)$ & $p$ value & $\overline{\text { Overall } p \text { value }}$ \\
\hline \multicolumn{4}{|l|}{$\geq 1$ Unprofessional behavior } \\
\hline Emotional exhaustion (for each 1 point higher) & $1.03(1.02,1.04)$ & & $<0.0001$ \\
\hline Male vs. female & $0.98(0.71,1.35)$ & & 0.88 \\
\hline Age (for each year older) & $0.98(0.97,1.00)$ & & 0.01 \\
\hline Internal medicine or pediatric subspecialty (vs. primary care) & $1.12(0.72,1.75)$ & 0.61 & 0.27 \\
\hline Other medical specialty (vs. primary care) & $0.89(0.60,1.32)$ & 0.58 & \\
\hline Surgical specialty (vs. primary care) & $0.73(0.48,1.11)$ & 0.14 & \\
\hline Hours per week (for each additional hour) & $1.00(0.99,1.01)$ & & 0.59 \\
\hline Nights on call per week (for each additional night) & $0.96(0.90,1.03)$ & & 0.29 \\
\hline Academic medical center (vs. private practice) & $0.61(0.42,0.88)$ & 0.01 & 0.03 \\
\hline Active military (vs. private practice) & $0.43(0.12,1.52)$ & 0.19 & \\
\hline Other practice (vs. private practice) & $0.89(0.60,1.33)$ & 0.58 & \\
\hline Veterans hospital (vs. private practice) & $0.34(0.11,1.08)$ & 0.07 & \\
\hline \multicolumn{4}{|l|}{$\geq 1$ Unprofessional behavior } \\
\hline Depersonalization (for each 1 point higher) & $1.09(1.06,1.12)$ & & $<0.0001$ \\
\hline Male vs. female & $0.83(0.60,1.15)$ & & 0.26 \\
\hline Age (for each year older) & $0.99(0.98,1.00)$ & & 0.12 \\
\hline Internal medicine or pediatric subspecialty (vs. primary care) & $1.13(0.72,1.77)$ & 0.60 & 0.20 \\
\hline Other medical specialty (vs. primary care) & $0.84(0.56,1.25)$ & 0.40 & \\
\hline Surgical specialty (vs. primary care) & $0.71(0.46,1.08)$ & 0.11 & \\
\hline Hours per week (for each additional hour) & $1.00(0.99,1.01)$ & & 0.42 \\
\hline Nights on call per week (for each additional night) & $0.97(0.91,1.04)$ & & 0.42 \\
\hline Academic medical center (vs. private practice) & $0.61(0.42,0.88)$ & 0.01 & 0.03 \\
\hline Active military (vs. private practice) & $0.33(0.09,1.25)$ & 0.10 & \\
\hline Other practice (vs. private practice) & $0.86(0.57,1.28)$ & 0.45 & \\
\hline Veterans hospital (vs. private practice) & $0.32(0.10,1.03)$ & 0.06 & \\
\hline
\end{tabular}




\section{APPENDIX 4}

Table 6 Multivariable Analysis of Factors Associated with Each Cost-Conscious Attitude Item and Burnout

\begin{tabular}{|c|c|c|c|}
\hline & OR $(95 \% \mathrm{CI})$ & $p$ value & Overall $p$ value \\
\hline \multicolumn{4}{|c|}{ Disagree or strongly disagree w. "It is unfair to ask physicians to be cost-conscious and still keep the welfare of their patients foremost in their minds.' } \\
\hline Burnout & $1.58(1.16,2.14)$ & & 0.003 \\
\hline Male vs. Female & $0.94(0.69,1.29)$ & & 0.70 \\
\hline Age (for each year older) & $1.00(0.99,1.01)$ & & 0.89 \\
\hline Internal medicine or pediatric subspecialty (vs. primary care) & $0.92(0.59,1.41)$ & 0.69 & 0.94 \\
\hline Other medical specialty (vs. primary care) & $1.02(0.69,1.49)$ & 0.93 & \\
\hline Surgical specialty (vs. primary care) & $0.91(0.60,1.38)$ & 0.67 & \\
\hline Hours per week (for each additional hour) & $1.01(1.00,1.02)$ & & 0.03 \\
\hline Nights on call per week (for each additional night) & $0.93(0.87,0.99)$ & & 0.03 \\
\hline Academic medical center (vs. private practice) & $1.58(1.09,2.27)$ & 0.02 & 0.17 \\
\hline Active military (vs. private practice) & $0.87(0.26,2.97)$ & 0.83 & \\
\hline Other practice (vs. private practice) & $1.27(0.87,1.85)$ & 0.22 & \\
\hline Veterans hospital (vs. private practice) & $1.27(0.42,3.80)$ & 0.67 & \\
\hline \multicolumn{4}{|c|}{ Disagree or strongly disagree w. "Doctors are too busy to worry about the costs of tests and procedures." } \\
\hline Burnout & $2.05(1.48,2.84)$ & & $<0.0001$ \\
\hline Male vs. female & $1.07(0.77,1.49)$ & & 0.70 \\
\hline Age (for each year older) & $1.02(1.00,1.03)$ & & 0.01 \\
\hline Internal medicine or pediatric subspecialty (vs. primary care) & $1.04(0.66,1.65)$ & 0.86 & 0.75 \\
\hline Other medical specialty (vs. primary care) & $0.99(0.66,1.49)$ & 0.97 & \\
\hline Surgical specialty (vs. primary care) & $1.25(0.80,1.97)$ & 0.33 & \\
\hline Hours per week (for each additional hour) & $1.00(0.99,1.01)$ & & 0.76 \\
\hline Nights on call per week (for each additional night) & $1.00(0.93,1.07)$ & & 0.94 \\
\hline Academic medical center (vs. private practice) & $1.14(0.77,1.69)$ & 0.52 & 0.88 \\
\hline Active military (vs. private practice) & $1.61(0.40,6.39)$ & 0.50 & \\
\hline Other practice (vs. private practice) & $0.95(0.63,1.42)$ & 0.80 & \\
\hline Veterans hospital (vs. private practice) & $1.30(0.38,4.42)$ & 0.68 & \\
\hline \multicolumn{4}{|c|}{ Agree or strongly agree "It is my responsibility to try to contain health care costs." } \\
\hline Burnout & $1.60(1.12,2.28)$ & & 0.01 \\
\hline Male vs. female & $1.06(0.73,1.54)$ & & 0.75 \\
\hline Age (for each year older) & $1.00(0.99,1.02)$ & & 0.59 \\
\hline Internal medicine or pediatric subspecialty (vs. primary care) & $1.32(0.75,2.30)$ & 0.34 & 0.03 \\
\hline Other medical specialty (vs. primary care) & $0.65(0.42,1.01)$ & 0.06 & \\
\hline Surgical specialty (vs. primary care) & $0.70(0.43,1.12)$ & 0.14 & \\
\hline Hours per week (for each additional hour) & $1.00(0.99,1.01)$ & & 0.56 \\
\hline Nights on call per week (for each additional night) & $0.96(0.90,1.04)$ & & 0.35 \\
\hline Academic medical center (vs. private practice) & $1.83(1.18,2.84)$ & 0.01 & 0.01 \\
\hline Active military (vs. private practice) & $0.58(0.17,2.03)$ & 0.40 & \\
\hline Other practice (vs. private practice) & $1.59(1.01,2.49)$ & 0.05 & \\
\hline Veterans hospital (vs. private practice) & $5.87(0.74,46.4)$ & 0.09 & \\
\hline \multicolumn{4}{|c|}{ Agree or strongly agree with "Cost to society is important in my decisions to use or not to use an intervention." } \\
\hline Burnout & $1.02(0.75,1.40)$ & & 0.89 \\
\hline Male vs. female & $1.04(0.75,1.43)$ & & 0.83 \\
\hline Age (for each year older) & $0.99(0.98,1.01)$ & & 0.22 \\
\hline Internal medicine or pediatric subspecialty (vs. primary care) & $0.89(0.57,1.39)$ & 0.60 & 0.91 \\
\hline Other medical specialty (vs. primary care) & $0.94(0.63,1.40)$ & 0.76 & \\
\hline Surgical specialty (vs. primary care) & $1.04(0.68,1.60)$ & 0.84 & \\
\hline Hours per week (for each additional hour) & $1.01(1.00,1.02)$ & & 0.17 \\
\hline Nights on call per week (for each additional night) & $0.94(0.88,1.01)$ & & 0.09 \\
\hline Academic medical center (vs. private practice) & $1.67(1.13,2.45)$ & 0.01 & 0.06 \\
\hline Active military (vs. private practice) & $1.68(0.43,6.49)$ & 0.45 & \\
\hline Other practice (vs. private practice) & $1.05(0.71,1.54)$ & 0.80 & \\
\hline Veterans hospital (vs. private practice) & $0.56(0.18,1.72)$ & 0.31 & \\
\hline \multicolumn{4}{|c|}{ Disagree or strongly disagree w. "There is currently too much emphasis on costs of tests and procedures." } \\
\hline Burnout & $1.03(0.76,1.40)$ & & 0.86 \\
\hline Male vs. female & $1.17(0.85,1.61)$ & & 0.32 \\
\hline Age (for each year older) & $1.00(0.98,1.01)$ & & 0.70 \\
\hline Internal medicine or pediatric subspecialty (vs. primary care) & $1.11(0.72,1.72)$ & 0.62 & 0.55 \\
\hline Other medical specialty (vs. primary care) & $1.33(0.90,1.96)$ & 0.15 & \\
\hline Surgical specialty (vs. primary care) & $1.10(0.73,1.66)$ & 0.66 & \\
\hline Hours per week (for each additional hour) & $1.00(0.99,1.01)$ & & 0.65 \\
\hline Nights on call per week (for each additional night) & $0.96(0.90,1.03)$ & & 0.29 \\
\hline Academic medical center (vs. private practice) & $1.47(1.02,2.12)$ & 0.04 & 0.08 \\
\hline Active military (vs. private practice) & $0.46(0.13,1.61)$ & 0.22 & \\
\hline Other practice (vs. private practice) & $1.45(0.98,2.13)$ & 0.06 & \\
\hline & & 0.61 & \\
\hline \multicolumn{4}{|c|}{ Disagree/strongly disagree w. "I try not to think about the cost to the health care system when making treatment decisions." } \\
\hline Burnout & $1.08(0.79,1.47)$ & & 0.63 \\
\hline Male vs. female & $1.04(0.75,1.43)$ & & 0.83 \\
\hline Age (for each year older) & $1.00(0.98,1.01)$ & & 0.52 \\
\hline Internal medicine or pediatric subspecialty (vs. primary care) & $0.77(0.49,1.18)$ & 0.23 & 0.30 \\
\hline
\end{tabular}


Table 6. (continued)

\begin{tabular}{|c|c|c|c|}
\hline & OR $(95 \%$ CI $)$ & $p$ value & Overall $p$ value \\
\hline Other medical specialty (vs. primary care) & $1.13(0.76,1.67)$ & 0.55 & \\
\hline Surgical specialty (vs. primary care) & $1.12(0.73,1.72)$ & 0.60 & \\
\hline Hours per week (for each additional hour) & $1.00(0.99,1.01)$ & & 0.37 \\
\hline Nights on call per week (for each additional night) & $0.97(0.90,1.03)$ & & 0.31 \\
\hline Academic medical center (vs. private practice) & $1.09(0.75,1.59)$ & 0.66 & 0.04 \\
\hline Active military (vs. private practice) & $0.29(0.08,1.02)$ & 0.05 & \\
\hline Other practice (vs. private practice) & $0.83(0.56,1.22)$ & 0.34 & \\
\hline Veterans hospital (vs. private practice) & $0.28(0.09,0.86)$ & 0.03 & \\
\hline
\end{tabular}

\section{APPENDIX 5}

Table 7 Multivariable Analysis of Factors Associated with Mean Cost-Conscious Score, Including Emotional Exhaustion, and Depersonalization

\begin{tabular}{|c|c|c|c|}
\hline & $\begin{array}{l}\text { Parameter estimate } \\
(\mathbf{9 5 \%} \text { CI) }\end{array}$ & $p$ value & $\overline{\text { Overall } p \text { value }}$ \\
\hline \multicolumn{4}{|l|}{ High emotional exhaustion* } \\
\hline High emotional exhaustion & $-0.85(-1.40,-0.30)$ & & 0.003 \\
\hline Male vs. female & $-0.04(-0.61,0.54)$ & & 0.90 \\
\hline Age (for each year older) & $0.006(-0.02,0.03)$ & & 0.64 \\
\hline Internal medicine or pediatric subspecialty (vs. primary care) & $-0.06(-0.84,0.72)$ & 0.87 & 0.99 \\
\hline Other medical specialty (vs. primary care) & $-0.04(-0.74,0.66)$ & 0.91 & \\
\hline Surgical specialty (vs. primary care) & $-0.03(-0.78,0.72)$ & 0.94 & \\
\hline Hours per week (for each additional hour) & $0.008(-0.01,0.03)$ & & 0.33 \\
\hline Nights on call per week (for each additional night) & $-0.07(-0.19,0.05)$ & & 0.28 \\
\hline Academic medical center (vs. private practice) & $0.84(0.19,1.50)$ & 0.01 & 0.06 \\
\hline Active military (vs. private practice) & $-1.35(-3.53,0.83)$ & 0.22 & \\
\hline Other practice (vs. private practice) & $0.34(-0.35,1.03)$ & 0.33 & \\
\hline Veterans hospital (vs. private practice) & $-0.14(-2.16,1.88)$ & 0.89 & \\
\hline \multicolumn{4}{|l|}{ High depersonalization ${ }^{\dagger}$} \\
\hline High depersonalization & $-0.64(-1.22,-0.06)$ & & 0.03 \\
\hline Male vs. female & $0.11(-0.46,0.68)$ & & 0.70 \\
\hline Age (for each year older) & $0.005(-0.02,0.03)$ & & 0.70 \\
\hline Internal medicine or pediatric subspecialty (vs. primary care) & $-0.05(-0.83,0.73)$ & 0.90 & 0.99 \\
\hline Other medical specialty (vs. primary care) & $-0.02(-0.72,0.68)$ & 0.95 & \\
\hline Surgical specialty (vs. primary care) & $-0.02(-0.77,0.73)$ & 0.96 & \\
\hline Hours per week (for each additional hour) & $0.005(-0.01,0.02)$ & & 0.59 \\
\hline Nights on call per week (for each additional night) & $-0.08(-0.20,0.04)$ & & 0.20 \\
\hline Academic medical center (vs. private practice) & $0.87(0.21,1.53)$ & 0.01 & 0.05 \\
\hline Active military (vs. private practice) & $-1.37(-3.56,0.82)$ & 0.22 & \\
\hline Other practice (vs. private practice) & $0.38(-0.31,1.07)$ & 0.28 & \\
\hline Veterans hospital (vs. private practice) & $-0.12(-2.15,1.90)$ & 0.91 & \\
\hline \multicolumn{4}{|l|}{ Emotional exhaustion, continuous } \\
\hline Emotional exhaustion (for each 1 point higher) & $-0.03(-0.06,-0.01)$ & & $<0.01$ \\
\hline Male vs. female & $-0.05(-0.62,0.52)$ & & 0.86 \\
\hline Age (for each year older) & $0.004(-0.02,0.03)$ & & 0.73 \\
\hline Internal medicine or pediatric subspecialty (vs. primary care) & $-0.13(-0.91,0.65)$ & 0.75 & 0.99 \\
\hline Other medical specialty (vs. primary care) & $-0.06(-0.76,0.63)$ & 0.86 & \\
\hline Surgical specialty (vs. primary care) & $-0.07(-0.82,0.67)$ & 0.85 & \\
\hline Hours per week (for each additional hour) & $0.01(-0.008,0.03)$ & & 0.30 \\
\hline Nights on call per week (for each additional night) & $-0.06(-0.18,0.06)$ & & 0.31 \\
\hline Academic medical center (vs. private practice) & $0.83(0.18,1.49)$ & 0.01 & 0.06 \\
\hline Active military (vs. private practice) & $-1.39(-3.57,0.79)$ & 0.21 & \\
\hline Other practice (vs. private practice) & $0.38(-0.31,1.06)$ & 0.28 & \\
\hline Veterans hospital (vs. private practice) & $-0.17(-2.19,1.85)$ & 0.87 & \\
\hline \multicolumn{4}{|l|}{ Depersonalization, continuous } \\
\hline Depersonalization (for each 1 point higher) & $-0.06(-0.10,-0.02)$ & & $<0.01$ \\
\hline Male vs. female & $0.12(-0.44,0.69)$ & & 0.67 \\
\hline Age (for each year older) & $0.001(-0.02,0.03)$ & & 0.94 \\
\hline Internal medicine or pediatric subspecialty (vs. primary care) & $-0.09(-0.87,0.69)$ & 0.81 & 0.99 \\
\hline Other medical specialty (vs. primary care) & $-0.02(-0.72,0.67)$ & 0.95 & \\
\hline Surgical specialty (vs. primary care) & $-0.03(-0.77,0.72)$ & 0.94 & \\
\hline Hours per week (for each additional hour) & $0.01(-0.01,0.02)$ & & 0.50 \\
\hline Nights on call per week (for each additional night) & $-0.08(-0.20,0.04)$ & & 0.20 \\
\hline Academic medical center (vs. private practice) & $0.84(0.18,1.49)$ & 0.01 & 0.07 \\
\hline Active military (vs. private practice) & $-1.23(-3.41,0.95)$ & 0.27 & \\
\hline Other practice (vs. private practice) & $0.42(-0.27,1.11)$ & 0.23 & \\
\hline Veterans hospital (vs. private practice) & $-0.11(-2.13,1.91)$ & 0.92 & \\
\hline
\end{tabular}

*High emotional exhaustion $(\geq 27)$ using established cut-off scores

$\dagger$ High depersonalization $\geq 10$ ) using established cut-off scores 